\title{
Percent Predicted Total Lung Capacity
}

National Cancer Institute

\section{Source}

National Cancer Institute. Percent Predicted Total Lung Capacity. NCI Thesaurus. Code C112388.

The total volume of air in the lungs after maximum inhalation as a proportion of the predicted normal value. (CDISC) 